\title{
Investigation of availability and accessibility of community automated external defibrillators in a territory in Hong Kong
}

\author{
CL Ho, CT Lui *, KL Tsui, CW Kam
}

\section{A B S T R A C T}

Objective: To evaluate the availability and accessibility of community automated external defibrillators in a territory in Hong Kong.

Design: Cross-sectional study.

Setting: Two public hospitals in New Territories West Cluster in Hong Kong.

Participants: Information about the locations of community automated external defibrillators was obtained from automated external defibrillator suppliers and through community search. Data on locations of out-of-hospital cardiac arrests from August 2010 to September 2013 were obtained from the local cardiac arrest registry of the emergency departments of two hospitals. Sites of both automated external defibrillators and out-of-hospital cardiac arrests were geographically coded and mapped. The number of out-of-hospital cardiac arrests within $100 \mathrm{~m}$ of automated external defibrillators per year and the proportion of out-of-hospital cardiac arrests with accessible automated external defibrillators $(100 \mathrm{~m})$ were calculated. The number of community automated external defibrillators per 10000 population and public access defibrillation rate were also calculated and compared with those in other countries. automated external defibrillators in the territory. The number of automated external defibrillators per 10000 population was 1.942. All facilities with automated external defibrillators in this territory had more than 0.2 out-of-hospital cardiac arrests per automated external defibrillator per year within $100 \mathrm{~m}$. Among all out-of-hospital cardiac arrests, $25.2 \%$ could have an automated external defibrillator reachable within $100 \mathrm{~m}$. The public access defibrillation rate was $0.168 \%$.

Conclusions: The number and accessibility of community automated external defibrillators in this territory are comparable to those in other developed countries. The placement site of community automated external defibrillators is cost-effective. However, the public access defibrillation rate is low.

\section{Hong Kong Med J 2014;20:371-8 \\ DOI: 10.12809/hkmj144258 \\ CL Ho, MB, ChB \\ CT Lui *, FHKCEM, FHKAM (Emergency Medicine) \\ KL Tsui, FHKCEM, FHKAM (Emergency Medicine) \\ CW Kam, FHKCEM, FHKAM (Emergency Medicine) \\ Department of Accident and Emergency Medicine, Tuen Mun Hospital, Tuen Mun, Hong Kong}

Results: There were a total of 207 community * Corresponding author: ectlui@yahoo.com.hk

New knowledge added by this study

- The number and accessibility of community automated external defibrillators (AEDs) in New Territories West region are comparable to those in other developed countries.

- All the placement sites of community AEDs in New Territories West region are cost-effective.

- The public access defibrillation (PAD) rate is low in New Territories West region.

Implications for clinical practice or policy

- Central AED registry for optimising placement of AED, education to laypersons, legal support for bystander cardiopulmonary resuscitation and AED use might be important for improving PAD rate.

\section{Introduction}

The survival rate of out-of-hospital cardiac arrest (OHCA) is low in Hong Kong. The reported overall survival-to-admission rate in recent local studies ranged from $12.7 \%$ to $14.6 \%$, while the survival-todischarge rate ranged from $1.25 \%$ to $3.0 \% .^{1-5}$ In the first few minutes after OHCA, rapid implementation of five critical actions including early access, early cardiopulmonary resuscitation (CPR), rapid and effective defibrillation, early advanced life support, and comprehensive post-cardiac arrest care can strengthen the "chain of survival",6,7 A study including 1737 patients found that, within 4 minutes of collapse, approximately $53 \%$ of patients were in ventricular fibrillation/tachycardia. ${ }^{8}$ Many studies have already shown that rapid defibrillation with automated external defibrillators (AEDs) by nonparamedics can improve survival. ${ }^{9-12}$ In public access 


\section{在香港一社區內自動體外心臟去顫器的 可用性和取用率 \\ 何植良、雷俊達、徐國樑、甘澤華}

目的：評估香港一社區內自動體外心藏去顫器的可用性和取用率。

設計：㮨斷面研究。

安排：香港新界西聯網內的兩間公立醫院。

參與者：從自動體外心藏去顫器的供應商和社區搜索有關擺放社區自 動體外心臟去顫器的位置。另外, 從兩家醫院急診室的心臟停搏資料 庫找出 2010 年 8 月至 2013 年 9 月期間發生院外心藏停搏的地方。然後 把去顫器的分佈地點和發生院外心臟停搏的地方進行地域編碼和映 射, 分別計算出每年在去顫器位置 100 米範圍以內所發生的院外心臟 停搏的次數, 以及院外心藏停搏和去顫器位置 100 米範圍內的取用比 例, 亦計算平均每一萬人社區自動體外心臟去顫器的數量和公眾除顫 率, 並與其他國家的數據比較。

結果：香港新界西聯網內共有 207 個社區自動體外心臟去顫器。平均 每一萬人有1.942個自動體外心藏去顫器。新界西聯網內所有安裝去 顫器的設施的 100 米範圍內, 平均每個去顫器有 0.2 宗院外心藏停搏事 件。院外心藏停搏事件中有 $25.2 \%$ 均可於 100 米範圍內取得自動體外心 臟去顫器。公眾除顫率為 $0.168 \%$ 。

結論：社區自動體外心臟去顫器的數量和取用率與其他發達國家相 若。本研究發現社區自動體外心臟去顫器的安置點具成本效益, 但公 眾除顫率屬偏低。 defibrillation (PAD), laypersons can have access to AED so that defibrillation can be delivered at the earliest before ambulance arrival. The concept of PAD has been well adopted in basic life support (BLS) training. However, the utilisation rate of AED was low in Hong Kong in a previous study. ${ }^{13}$ With the undoubtful benefit of PAD on the outcome of OHCA, it is invaluable to explore the reasons behind low PAD rate.

The successful delivery of PAD for cardiac arrest patients outside hospitals depends on a chain of factors including adequate number of AEDs in the community, close proximity of the AED to the site of OHCA (satisfactory matching of site of AED and OHCA), knowledge of bystanders and laypersons in BLS and how to use AED and, eventually, willingness of bystanders to use AED. Minimising mismatch between the site of AED placement and the site of OHCA would maximise the chances of PAD and improve the outcomes of OHCA. A significant association has been demonstrated between the matching and cost-effectiveness of AED placement. ${ }^{14}$

The objective of our study was to evaluate the availability and accessibility of AEDs in a territory in Hong Kong. We evaluated the total number of AEDs in the community and their geographical distribution throughout the territory. In addition, we assessed the matching of AED placement site and the site of OHCA.

\section{Methods}

\section{Study design and setting}

This was a cross-sectional study performed in the New Territories West region of Hong Kong. The region includes urban town area and rural area in the districts of Yuen Long, Tin Shui Wai, and Tuen Mun. According to data from the 2011 Census, the residential population of the region was $1066075^{15}$ and the area of the territory was $223 \mathrm{~km}^{2}{ }^{2}{ }^{16,17}$ There were only two hospitals with acute emergency services in the territory. All OHCAs were delivered to either hospital.

\section{Study population}

Data on all OHCAs in the territory were obtained from the local cardiac arrest registry which prospectively collects data on all OHCA cases managed in the emergency departments of the two hospitals. All data were recorded in Utstein style. The study period was from August 2010 to September 2013. Patients with traumatic cardiac arrest and deaths with postmortem changes were excluded. A total of 1936 cases were retrieved. Within those, 20 cases were excluded because these were in-hospital cardiac arrests in mental hospitals; 53 cases were excluded because of non-traceable site of arrest; 78 cases were excluded because of incomplete address. Overall, 1785 cases were included in the analysis. For OHCAs occurring at home or in institutions, the sites of arrest information were retrieved from the hospital database in the admission office. For OHCAs occurring outside home or institutions, data were traced from either the hospital records or ambulance records. Moreover, the PAD rate was retrieved from the registry, and double-checked with the hospital medical records and ambulance record. Public access defibrillation rate was defined as the rate of pre-hospital defibrillations performed by laypersons in patients with OHCA. It was calculated by dividing the total number of PAD cases by the total number of OHCAs.

\section{Accessibility of automated external defibrillator in an episode of cardiac arrest}

According to the American Heart Association (AHA) recommendation, a community AED is regarded as accessible if it can be transported to the patient by a layperson by brisk walking within 1 to 1.5 minutes. ${ }^{14}$ For human beings, the average speed of brisk walking is around $8 \mathrm{~km}$ per hour, ie $2.2 \mathrm{~m}$ per second. A layperson can travel $200 \mathrm{~m}$ within 1.5 minutes. So, an AED is defined as being accessible if it is located within $100 \mathrm{~m}$ of a cardiac arrest patient (layperson travels $100 \mathrm{~m}$ to get the AED and travels $100 \mathrm{~m}$ to save the victim) ${ }^{18}$ Accessibility of AED in an arrest episode was also reported with various timeframes from 1 to 5 minutes of brisk walking speed. 


\section{Locations of automated external defibrillators}

Since there was no AED registry in Hong Kong, obtaining the data on the site of AED was difficult. We exhausted all methods to trace all AEDs in the community throughout the territory. There were two sources of data on the locations of AEDs. Firstly, we searched all AEDs in the community as per the information from the suppliers. All suppliers registered on the Medical Device Control Office of the Department of Health for external defibrillators were contacted for purchase records. Other brands of AEDs were traced from contacts with BLS training centres. Data about the locations of AEDs were obtained from sales registers of suppliers. In total, five brands of AED suppliers were contacted including Cardio Science, Physio-control, Laerdal, Philips, and Metrax. The second source was through community search. Staff at all schools, sport facilities, swimming pools, old-age homes and other hostels, shopping malls, housing estates, and public facilities in the territory were contacted by emails, telephone calls, or personal visits to confirm the existence of AEDs. The list of public facilities was found by Internet search and included government webpages. The information of locations of community AEDs was obtained for the period from September to December 2013.

The numbers of AEDs located in the searched facilities were reported as percentages. For all AEDs located in different facilities, we evaluated the number of OHCAs that occurred within $100 \mathrm{~m}$ throughout the study period, and calculated the average number of OHCAs that occurred around the AED per year.

According to AHA recommendation, AED should be placed where there is likely one cardiac arrest within $100 \mathrm{~m}$ in 5 years. ${ }^{14}$ In other words, the AED installation was regarded as cost-effective if there were more than 0.2 OHCA per AED per year within $100 \mathrm{~m}$

The availability of AED can be reflected by the AED density and the number of AEDs per 10000 population. The AED density was calculated by dividing the total number of AEDs by the area of the territory. The number of AEDs per 10000 population was calculated with the data of residential population from the Census data. We searched the literature to obtain similar data from studies in other countries, including Japan, Singapore, Denmark, Austria, and the US for comparison and illustration.

\section{Methodology for geographical mapping and statistics}

Locations of all cardiac arrests in this cluster were geographically coded by the Google Map (http:// maps.google.com.hk) to longitudes and latitudes. The longitudes and latitudes of the centre of the corresponding building were coded. The precision was up to 6 decimal degrees which implies a maximum error of coordinate of $11.3 \mathrm{~cm}$. For $\mathrm{OHCAs}$ that occurred in an open area, the geocoding was performed with best achievable precision according to information from the ambulance record or hospital record. The sites of AEDs in this cluster were also located and geographically coded. The distance between each case of OHCA and AED was calculated using the Haversine formula. ${ }^{18}$ Geographical mapping was performed using scripts with Google Map.

Statistical analysis was performed with IBM SPSS 20. Categorical variables were shown in proportions and percentages. Continuous variables of distance were presented as medians and interquartile ranges for data with skewed distribution. Categorical data were compared using Chi squared test. Distances were compared with

TABLE I. Automated external defibrillator in various types of facilities throughout the territory

\begin{tabular}{|c|c|c|c|c|c|}
\hline Type of facility & No. of AEDs & $\begin{array}{l}\text { Total no. of facilities } \\
\text { in the region }\end{array}$ & $\begin{array}{l}\% \text { Of facilities } \\
\text { with AEDs }\end{array}$ & $\begin{array}{l}\text { No. of OHCAs } \\
\text { within } 100 \mathrm{~m}\end{array}$ & $\begin{array}{c}\text { Average OHCA/ } \\
\text { AED/year }\end{array}$ \\
\hline Community clinics & 30 & 175 & $17.1 \%$ & 71 & 0.747 \\
\hline Housing estates & 13 & 73 & $17.8 \%$ & 15 & 0.364 \\
\hline Hostels or institutions & 16 & 83 & $19.3 \%$ & 105 & 2.072 \\
\hline Train stations & 5 & $\begin{array}{c}5 \\
73^{\star}\end{array}$ & $\begin{array}{l}100 \% \\
6.8 \%\end{array}$ & 4 & 0.253 \\
\hline Parks & 6 & 6 & $100 \%$ & 4 & 0.210 \\
\hline Police stations & 7 & 7 & $100 \%$ & 7 & 0.315 \\
\hline Schools & 78 & 163 & $47.9 \%$ & 206 & 0.834 \\
\hline Shopping malls & 13 & 50 & $26 \%$ & 35 & 0.850 \\
\hline Sports stadiums & 35 & 35 & $100 \%$ & 98 & 0.884 \\
\hline Others & 4 & - & - & 3 & 0.237 \\
\hline Total & 207 & 670 & - & 548 & 0.836 \\
\hline
\end{tabular}

Abbreviations: AED = automated external defibrillator; OHCA = out-of-hospital cardiac arrest

* Includes Light Railway stations 
independent sample median test. $\mathrm{P}$ values of less than 0.05 were regarded as significant.

\section{Ethical considerations}

The research was approved by the Cluster Clinical Research and Ethics Committee.

\section{Results}

\section{The site of community automated external} defibrillator

A total of 674 public facilities were found in the search and enquired for the installation of AED (Table 1). The response rate was satisfactory with only two schools failing to respond to our enquiry. A total of 207 community AEDs were found and located. Among them, 180 were identified from the registers of suppliers and 27 through community search. The geographical location of the AEDs in the territory is shown in Figure a.

The characteristics of community AEDs in various types of facilities are shown in Table 1. Schools possessed most of the community AEDs $(n=78)$, followed by sports stadiums $(n=35)$, community clinics $(n=30)$, and hostels $(n=16)$. All major parks and sports stadiums, and nearly half the schools in the territory had installed AEDs. Less than $20 \%$ of housing estates and hostels had been equipped with AEDs.

The number of OHCAs occurring per AED per year in various facilities is also shown in Table 1. Hostels or institutions had the most OHCAs per AED per year (2.072), followed by sports stadiums (0.884), shopping malls (0.850), and schools (0.834). All facilities with AEDs in the territory had more than 0.2 OHCA per AED per year within $100 \mathrm{~m}$.

\section{The number of automated external defibrillators per population and area}

The number of AEDs per 10000 population was 1.942 , and the AED density was 0.928 per $\mathrm{km}^{2}$ (Table 2). The number of AEDs per population and density of Singapore, Austria, Japan, Denmark, and the US are also shown in Table $2^{19-26}$ for comparison.

\section{Location of out-of-hospital cardiac arrests}

The geographical distribution of all OHCAs is shown in Figure b. The characteristics of OHCAs in various sites of cardiac arrest are shown in Table 3. More than half of OHCAs occurred at home (53.0\%) while one third occurred in the elderly's home (36.4\%) and $8.5 \%$ occurred in open areas. More patients with OHCAs in open areas and inside other buildings had received pre-hospital defibrillation versus those occurring in other locations. The median distance from the site of cardiac arrest to the nearest AED was lowest for cardiac arrest occurring in open areas. The proportion of OHCAs in open areas with
AEDs in reachable distance was higher compared with those occurring in other sites.

\section{Matching of out-of-hospital cardiac arrests with community automated external defibrillators}

Among all OHCAs, 25.2\% could have AEDs reachable within $100 \mathrm{~m}$ (1.5 minutes); $59.4 \%$ could
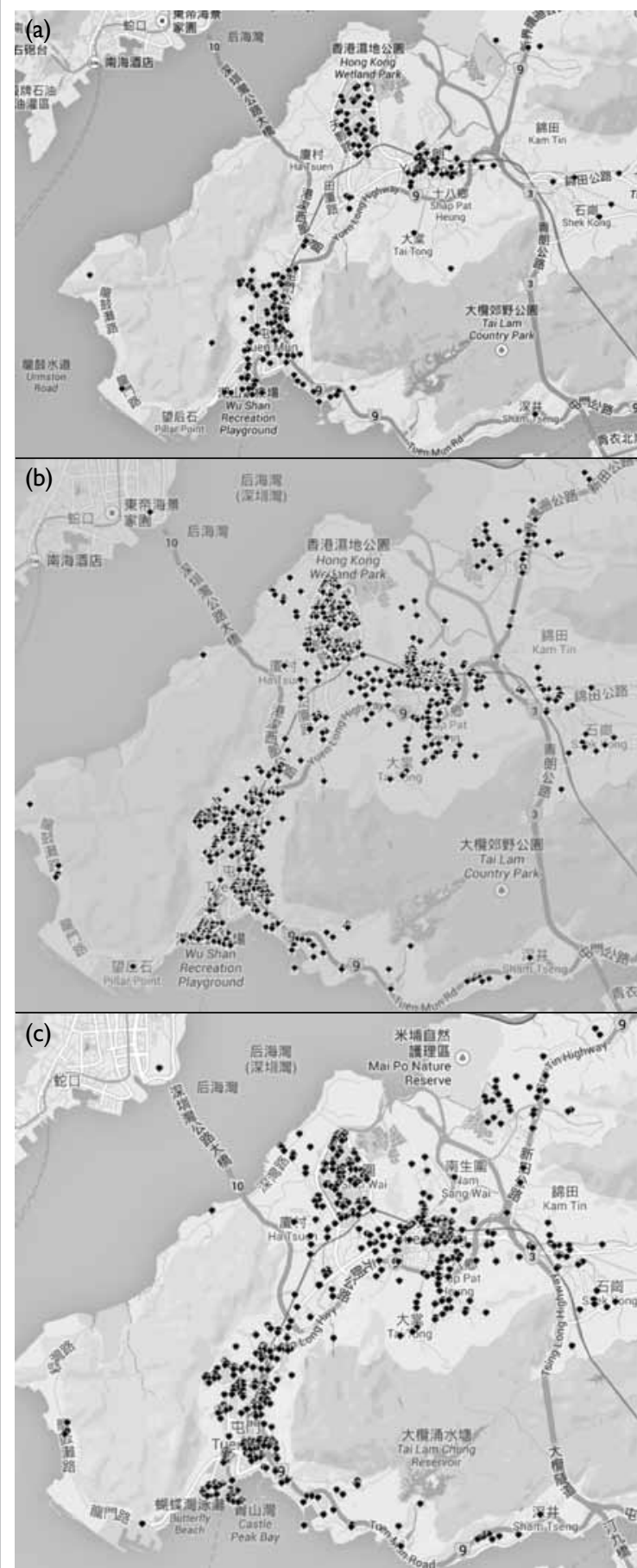

FIG. Mapping of automated external defibrillators (AEDs) and out-of-hospital cardiac arrests (OHCAs) throughout the territory

(a) Location of AEDs, (b) location of OHCAs throughout the study period, and (c) location of OHCAs where AED was not accessible within $100 \mathrm{~m}$ 
have AEDs available within 3 minutes $(200 \mathrm{~m})$ confirmation from hospital and pre-hospital records, [Table 4]. For cardiac arrests occurring in open 20 were performed by ambulance crew or other preareas, the proportion of cases with AEDs within hospital personnel. Only three (0.168\%) out of 1785 reachable distance $(100 \mathrm{~m})$ was higher than the had genuine PAD.

arrests happening in buildings (37.7\% vs $24.0 \%)$.

Of the 650 OHCAs occurring in old-age The difference was statistically significant $(\mathrm{P}<0.001)$. homes, 81 cases happened in hostels equipped with Figure $\mathrm{c}$ illustrates the distribution of OHCAs for AEDs. Public access defibrillation was delivered in which AEDs were not accessible within $100 \mathrm{~m}$.

\section{Public access defibrillation rate}

From the cardiac arrest registry, 23 out of 1785 OHCAs had documented PAD. However, with only one case. A total of $80(98.8 \%)$ cases of cardiac arrest events in hostels equipped with AEDs were not defibrillated. Cases where AED was applied but no shock delivered were not considered for calculating PAD rate.

TABLE 2. Automated external defibrillator per population and automated external defibrillator density in various countries

\begin{tabular}{|c|c|c|c|c|c|c|}
\hline & Year & No. of AEDs & $\begin{array}{c}\text { Population } \\
\left(x 1^{6}\right)\end{array}$ & $\begin{array}{l}\text { AED/10 } 000 \\
\text { population }\end{array}$ & Area $\left(\mathbf{k m}^{2}\right)$ & $\begin{array}{c}\text { Density } \\
\text { AED } / \mathrm{km}^{2}\end{array}$ \\
\hline New Territories West region of Hong Kong & 2013 & 207 & 1.066 & 1.942 & 223 & 0.928 \\
\hline Japan $^{19}$ & 2007 & 8826520 & 12720 & 6.978 & 37800020 & 0.234 \\
\hline Singapore ${ }^{20-22}$ & 2013 & 106421 & 5.39922 & 1.971 & 682.323 & 1.559 \\
\hline Copenhagen $^{23}$ & 2011 & 55224 & 0.60024 & 9.200 & 9724 & 5.691 \\
\hline Austria $^{24,25}$ & 2004 & 186525 & 8.4126 & 2.218 & 8400026 & 0.022 \\
\hline Metropolitan area in the US ${ }^{26}$ & 2006 & 173927 & 2.527 & 6.956 & 517827 & 0.336 \\
\hline
\end{tabular}

Abbreviation: AED = automated external defibrillator

TABLE 3. Cardiac arrests occurring in various sites during the study period

\begin{tabular}{|c|c|c|c|c|}
\hline Site of arrest & No. (\%) & $\begin{array}{c}\text { Pre-hospital } \\
\text { defibrillation delivered }\end{array}$ & $\begin{array}{l}\text { Median distance }(\mathrm{m}) \text { from site of } \\
\text { arrest to the nearest AED (IQR) }\end{array}$ & $\begin{array}{l}\text { AED accessible within } \\
100 \mathrm{~m}\end{array}$ \\
\hline Home & $946 / 1785$ (53.0\%) & $139 / 946(14.7 \%)$ & $167.3(198.1)$ & 238/946 (25.2\%) \\
\hline Old-age home & $650 / 1785$ (36.4\%) & $30 / 650(4.6 \%)$ & $181.0(153.4)$ & $142 / 650(21.8 \%)$ \\
\hline Inside other buildings & $38 / 1785$ (2.1\%) & 17/38 (44.7\%) & $149.4(180.3)$ & 12/38 (31.6\%) \\
\hline \multirow[t]{2}{*}{ Open areas } & $151 / 1785(8.5 \%)$ & 48/151 (31.8\%) & $132.1(162.2)$ & $57 / 151(37.7 \%)$ \\
\hline & & & $P=0.02^{*}$ & $P<0.001 \dagger$ \\
\hline
\end{tabular}

Abbreviations: AED = automated external defibrillator; $I Q R=$ interquartile range

* Independent sample median test

+ Chi squared test

TABLE 4. Matching between location of automated external defibrillator and out-of-hospital cardiac arrest

\begin{tabular}{|c|c|c|c|c|c|}
\hline \multirow[t]{2}{*}{ Distance } & \multirow{2}{*}{$\begin{array}{l}\text { Reachable time limit } \\
\text { at } 8 \mathrm{~km} / \mathrm{h}\end{array}$} & \multicolumn{3}{|c|}{ Case with AED nearby (\%) } & \multirow[t]{2}{*}{ P value } \\
\hline & & All OHCAs & OHCAs in open areas & OHCAs in buildings & \\
\hline \multicolumn{2}{|c|}{ Median distance from the nearest AED (IQR) } & $167.3(172.0)$ & $132.1(154.0)$ & $170.4(169.6)$ & $0.007^{*}$ \\
\hline $333 \mathrm{~m}$ & 5 Minutes & $1471 / 1785(82.4 \%)$ & $126 / 151(83.4 \%)$ & 1345/1634 (82.3\%) & $0.729 \dagger$ \\
\hline $267 \mathrm{~m}$ & 4 Minutes & $1310 / 1785$ (73.4\%) & $119 / 151(78.8 \%)$ & $1191 / 1634(72.9 \%)$ & $0.115 \dagger$ \\
\hline $200 \mathrm{~m}$ & 3 Minutes & $1060 / 1785(59.4 \%)$ & $105 / 151(69.5 \%)$ & $955 / 1634(58.4 \%)$ & $0.008 \dagger$ \\
\hline $133 \mathrm{~m}$ & 2 Minutes & $616 / 1785(34.5 \%)$ & $77 / 151(51.0 \%)$ & $539 / 1634$ (33.0\%) & $<0.001 \dagger$ \\
\hline $100 \mathrm{~m}$ & 1.5 Minutes & $449 / 1785(25.2 \%)$ & $57 / 151(37.7 \%)$ & $392 / 1634$ (24.0\%) & $<0.001 \dagger$ \\
\hline $66.7 \mathrm{~m}$ & 1 Minute & $222 / 1785(12.4 \%)$ & $45 / 151(29.8 \%)$ & $177 / 1634$ (10.8\%) & $<0.001 \dagger$ \\
\hline
\end{tabular}

Abbreviations: $\mathrm{AED}=$ automated external defibrillator; $\mathrm{IQR}=$ interquartile range; $\mathrm{OHCA}=$ out-of-hospital cardiac arrest

* Independent sample median test

† Chi squared test 


\section{Discussion}

The number of AEDs per 10000 population in our study (1.942) was comparable to that in Singapore (1.971) and Austria (2.218), but far behind that in Copenhagen (9.200), Japan (6.978), and the US (6.956).

More than half of the schools were equipped with AEDs. The high equipment rate was because of the 'Heart-safe School' project organised by the Hong Kong College of Cardiology. The project aimed to install AEDs in over 1000 primary, secondary, and special schools in Hong Kong. It also provided training on CPR and the operation of AEDs to school staff. ${ }^{27}$ In our community survey, among schools not equipped with AEDs, at least 12 had joined the project and would receive AED installation in coming years. Thus, in the coming years, most of the schools would be equipped with AEDs.

All facilities with AEDs in this territory had more than 0.2 OHCA per AED per year within $100 \mathrm{~m}$ (Table 1). Thus, the cost-effectiveness of AEDs located in various types of facilities was satisfactory.

More patients with OHCAs in open areas and inside other buildings had pre-hospital defibrillation, ie shockable rhythm (Table 3 ). The median distance from the site of arrest to the nearest AED was lowest for cardiac arrests occurring in open areas and the proportion of OHCAs in open areas with AEDs within reachable distance was higher. It implies that the accessibility of AEDs in OHCAs occurring in open areas was higher. This group of patients should benefit most from community AEDs.

The average number of $\mathrm{OHCA}$ events per AED was highest in old-age homes installed with AEDs (more than two events per AED per year), which was far higher than the recommended threshold of costeffective AED by AHA (0.2 event per AED per year). However, only 16 (19.3\%) out of 83 old-age homes in our study were installed with AEDs. Although there was high incidence of OHCAs, the proportion of patients with shockable rhythm in pre-hospital stage remained low (4.6\%) [Table 3]; consequently, the cost-effectiveness of placement of AEDs in old-age homes could not be concluded. In old-age homes with AED equipment, old-age home staff may be unable or reluctant to use AEDs. In our study, 98.8\% of cardiac arrests in old-age homes equipped with AEDs received no PAD. This suggests that apart from installing AEDs, BLS training and education should be provided to the old-age home staff to increase the PAD rate.

In our study, most OHCAs (53\%) occurred at home. However, OHCAs within coverage of AEDs $(100 \mathrm{~m})$ in housing estates was 0.364 event/AED/ year, which was lower than that in schools, shopping malls, and sports stadiums. This was related to the large area of the housing estates versus that in hostels or other public facilities. To improve the AED coverage, more AEDs are required to be installed in housing estates. Another alternative would be consideration of home AEDs in families with highrisk residents. However, the benefit of home AEDs remains doubtful. A randomised controlled trial from 2003 to 2005 has shown that home AEDs offered no benefit to high-risk residents. ${ }^{28}$ The study recruited 7001 survivors of anterior myocardial infarction who were not candidates for an implantable cardioverterdefibrillator. They were randomised to either calling emergency medical services (EMS) and performing CPR, or using AEDs, calling EMS and performing CPR. It was found that there was no significant reduction in mortality in the AED group despite most of the arrests occurring at home. The authors concluded that it was due to low event rate, high proportion of unwitnessed events, and underuse of AEDs.

Only 13 (26\%) of 50 shopping malls were equipped with AEDs, while the average event/AED/ year was high (0.850) for AEDs installed in this location. This implied that more AEDs should be installed in these buildings. With surge in tourism and increase in people flow in shopping malls, the incidence of OHCAs in shopping malls would be expected to be increased over time. Shopping malls should be encouraged to install AEDs and the staff should be provided with relevant training and education.

For the matching of locations of AEDs and OHCAs, 25.2\% of OHCAs occurred with accessible AEDs within $100 \mathrm{~m}$. This was slightly lower than that observed in a study in Copenhagen in 2011 (28.8\%) with the same definition. ${ }^{23}$ With the timeframe of

TABLE 5. Public access defibrillation rate in various countries

\begin{tabular}{|c|c|c|c|c|}
\hline & Year & No. of PADs delivered & No. of OHCAs & PAD rate \\
\hline New Territories West region of Hong Kong & $2010-2013$ & 3 & 1785 & $0.168 \%$ \\
\hline Japan $^{19}$ & $2005-2007$ & 462 & 312319 & $0.148 \%$ \\
\hline Metropolitan area in the US ${ }^{26}$ & 2006 & 26 & 1231 & $2.11 \%$ \\
\hline Copenhagen ${ }^{29}$ & 1994-2005 & 0 & 4828 & $0 \%$ \\
\hline North America ${ }^{30}$ & 2005-2007 & 163 & 14420 & $1.13 \%$ \\
\hline
\end{tabular}

Abbreviations: $O H C A=$ out-of-hospital cardiac arrest; PAD = public access defibrillation 
3 minutes, up to nearly $60 \%$ of OHCA events had AEDs within accessible distance of around $200 \mathrm{~m}$.

However, the PAD rate in our cluster was extremely low (0.168\%). The PAD rate is low all over the world; it is at most $2.11 \%$ in previous studies (Table 5). ${ }^{19,26,29,30}$ A study in Copenhagen found that no AED was ever used during the study period from 1994 to $2005 . .^{29}$ The authors attributed this to the recent installation of AEDs (predominantly in 2005) and low annual incidence of cardiac arrests near AEDs. There is no local study on this issue. The low usage rate might have several reasons. People might not know there is an AED nearby. There is no central registration of community AEDs in Hong Kong. Automated external defibrillators could be accessible but might not be visible. It is difficult for a bystander to find a community AED if he/she is not a staff of that community facility. Certainly, central registration of community AEDs could improve the problem. Bystanders could be informed how to access the nearest community AED after calling 999 if all community AED sites were registered. A study in the US showed that such emergency dispatch systems could improve the PAD rate. ${ }^{31}$ With sophistication in mobile technology, it is not difficult to develop softwares or Apps in mobile devices which could firstly provide the current location of the BLS provider by GPS (Global Positioning System), and then automatically locate the nearest reachable AED. The location of AEDs in the territory could be continuously updated with the central AED registry through the Internet. Furthermore, central mandatory AED registry could facilitate researches and auditing, which could provide insight on the PAD situation throughout the Hong Kong territories.

People may be reluctant to use community AEDs even if these are available. In a survey conducted in a shopping mall with AEDs in the US in 2001, it was found that the most common concern with using community AEDs was 'fear of using the machine incorrectly'. The second most common concern was 'fear of legal liability.32 Education of the public and providing legal support may help to change their belief. Lo et $\mathrm{a}^{33}$ suggested that a law offering 'Good Samaritan' protection against liability rescuers in Hong Kong could alleviate the uncertainties and increase the benefits of the PAD programme. However, such legal proceeding has not been carried forward in Hong Kong. Lack of explicit and clear legislation certainly decreases the willingness to use AEDs. Without law protection, rescuers may be afraid of being sued by the victims' families in case of failed resuscitation. As a result, it is no surprise that 'do no harm without any action including CPR' is the choice of most bystanders. ${ }^{4,34}$

Central AED registry for optimising placement of AED, education of laypersons, and legal support for bystanders providing CPR and using AED may be important for improving PAD rate and outcomes of OHCA. Further study on evaluation of laypersons' attitude towards AED use could provide more insights on this problem.

\section{Limitations of this study}

Without central registry, the list of community AEDs obtained from suppliers and through community search may not be exhaustive. The actual number of community AEDs might be underestimated. Information about PAD delivery was obtained predominantly from the registry and pre-hospital records. The number of OHCAs with AEDs applied but not defibrillated was not traceable. Automated external defibrillators might have been used but PAD not delivered in non-shockable rhythm. The rate of AED use might be underestimated. However, all studies on PAD had the same assumption and bias. There was potential time bias in that the installation time of community AED was unknown. Out-ofhospital cardiac arrests that occurred from August 2010 to September 2013 were included in the study. The cardiac events of patients might have occurred prior to AED installation.

The distance calculated in our study was the shortest distance. In-building travel time was not incorporated. There are plenty of buildings within in a housing estate, especially in urban areas, in Hong Kong. The distance of vertical lift was also not taken into account. The actual time and distance might be underestimated. Furthermore, the accuracy of geographical mapping was up to the level of the building, and there would be bias between the geographical coordinates and the exact location of AEDs. Furthermore, for those OHCAs that happened in open areas, the geocoding was performed at the best achievable precision according to the available information from the ambulance and hospital records; this might have been associated with information bias.

\section{Conclusions}

In the New Territories West region of Hong Kong, the number of AEDs per 10000 population was 1.942 and the accessibility within $100 \mathrm{~m}$ of OHCA was $25.2 \%$, both being comparable to those from other developed countries. Although the placement site of community AED was cost-effective, PAD rate at $0.168 \%$ was low.

\section{Acknowledgement}

We would like to thank Mr John Kit-shing Wong, Trauma Nurse Coordinator of Tuen Mun Hospital for his invaluable help on the data search.

\section{References}

1. Wong TW, Yeung KC. Out-of-hospital cardiac arrest: two 
and a half years experience of an accident and emergency department in Hong Kong. J Accid Emerg Med 1995;12:349.

2. Leung LP, Lo CM, Tong HK. Prehospital resuscitation of out-of-hospital cardiac arrest in Queen Mary Hospital. Hong Kong J Emerg Med 2000;7:191-6.

3. Fan KL, Leung LP. Prognosis of patients with ventricular fibrillation in out-of-hospital cardiac arrest in Hong Kong: prospective study. Hong Kong Med J 2002;8:318-21.

4. Chung $\mathrm{CH}$, Wong PC. A six-year prospective study of out-of-hospital cardiac arrest managed by a voluntary ambulance organization. Hong Kong J Emerg Med 2005;12:140-7.

5. Leung KL, Lui CT, Cheung KH, Tsui KL, Tang YH. Outcome and prognostic factors of patients in out-of hospital cardiac arrests presenting with non-shockable rhythm in Hong Kong. Hong Kong J Emerg Med 2012;19:6-12.

6. Cummins RO, Ornato JP, Thies WH, Pepe PE. Improving survival from sudden cardiac arrest: the "chain of survival" concept. A statement for health professionals from the Advanced Cardiac Life Support Subcommittee and the Emergency Cardiac Care Committee, American Heart Association. Circulation 1991;83:1832-47.

7. Travers AH, Rea TD, Bobrow BJ, et al. Part 4: CPR overview: 2010 American Heart Association Guidelines for Cardiopulmonary Resuscitation and Emergency Cardiovascular Care. Circulation 2010;122(18 Suppl 3):S676-84.

8. Herlitz J, Ekström L, Wennerblom B, Axelsson A, Bång A, Holmberg S. Type of arrhythmia at EMS arrival on scene in out-of-hospital cardiac arrest in relation to interval from collapse and whether a bystander initiated CPR. Am J Emerg Med 1996;14:119-23.

9. Valenzuela TD, Roe DJ, Nichol G, Clark LL, Spaite DW, Hardman RG. Outcomes of rapid defibrillation by security officers after cardiac arrest in casinos. $\mathrm{N}$ Engl J Med 2000;343:1206-9.

10. Hallstrom AP, Ornato JP, Weisfeldt M, et al. Public-access defibrillation and survival after out-of-hospital cardiac arrest. N Engl J Med 2004;351:637-46.

11. Weisfeld ML, Sitlani CM, Ornato JP, et al. Survival after application of automatic external defibrillators before arrival of the emergency medical system: evaluation in the resuscitation outcomes consortium population of 21 million. J Am Coll Cardiol 2010;55:1713-20.

12. Sanna T, La Torre G, de Waure C, et al. Cardiopulmonary resuscitation alone vs. cardiopulmonary resuscitation plus automated external defibrillator use by non-healthcare professionals: a meta-analysis on 1583 cases of out-ofhospital cardiac arrest. Resuscitation 2008;76:226-32.

13. Chan TH, Lui CT, Cheung KH, Tang YH, Tsui KL. Outcome predictors of patients in out-of-hospital cardiac arrests with pre-hospital defibrillation in Hong Kong. Hong Kong J Emerg Med 2013;20:131-7.

14. Aufderheide T, Hazinski MF, Nichol G, et al. Community lay rescuer automated external defibrillation programs: key state legislative components and implementation strategies: a summary of a decade of experience for healthcare providers, policymakers, legislators, employers, and community leaders from the American Heart Association Emergency Cardiovascular Care Committee, Council on Clinical Cardiology, and Office of State Advocacy. Circulation 2006;113;1260-70.

15. Census 2011, HKSAR. Available from: www.census2011. gov.hk. Accessed 2 Mar 2014.

16. Area of Tuen Mun. Available from: http://zh.wikipedia. org/wiki/\%E5\%B1\%AF\%E9\%96\%80\%E5\%8D\%80. Accessed 2 Mar 2014

17. Area of Yuen Long. Available from: http://zh.wikipedia. org/wiki/\%E5\%85\%83\%E6\%9C\%97\%E5\%8D\%80. Accessed 2 Mar 2014.

18. Sinnott RW. Virtues of the Haversine. Sky Telescope 1984;68:159.

19. Kitamura T, Iwami T, Kawamura T, Nagao K, Tanaka H, Hiraide A; Implementation Working Group for the AllJapan Utstein Registry of the Fire and Disaster Management Agency. Nationwide public-access defibrillation in Japan. N Engl J Med 2010;362:994-1004.

20. Community AED in Singapore. Available from: http:// www.myheart.org.sg/article/heart-safe-singapore/aedregistry/about/188. Accessed 2 Mar 2014.

21. Population Trends 2013. Available from: http://www. singstat.gov.sg. Accessed 2 Mar 2014.

22. Ong ME, Tan EH, Yan X, et al. An observational study describing the geographic-time distribution of cardiac arrests in Singapore: what is the utility of geographic information systems for planning public access defibrillation? (PADS Phase I). Resuscitation 2008;76:388-96.

23. Hansen CM, Wissenberg M, Weeke P, et al. Automated external defibrillators inaccessible to more than half of nearby cardiac arrests in public locations during evening, nighttime, and weekends. Circulation 2013;128:222431.

24. Fleischhackl R, Roessler B, Domanovits H, et al. Results from Austria's nationwide public access defibrillation (ANPAD) programme collected over 2 years. Resuscitation 2008;77:195-200.

25. Area and population of Austria. Available from: http:// en.wikipedia.org/wiki/Austria. Accessed 2 Mar 2014.

26. Rea TD, Olsufka M, Bemis B, et al. A populationbased investigation of public access defibrillation: role of emergency medical services care. Resuscitation 2010;81:163-7.

27. 'Heart-safe School' project. Available from: http://www. heartsafeschool.org.hk. Accessed 2 Mar 2014.

28. Bardy GH, Lee KL, Mark DB, et al. Home use of automated external defibrillators for sudden cardiac arrest. N Engl J Med 2008;358:1793-804.

29. Folke F, Lippert FK, Nielsen SL, et al. Location of cardiac arrest in a city center: strategic placement of automated external defibrillators in public locations. Circulation 2009;120:510-7.

30. Weisfeldt ML, Everson-Stewart S, Sitlani C, et al. Ventricular tachyarrhythmias after cardiac arrest in public versus at home. N Engl J Med 2011;364:313-21.

31. Rea T, Blackwood J, Damon S, Phelps R, Eisenberg M. A link between emergency dispatch and public access AEDs: potential implications for early defibrillation. Resuscitation 2011;82:995-8.

32. Lubin J, Chung SS, Williams K. An assessment of public attitudes toward automated external defibrillators. Resuscitation 2004;62:43-7.

33. Lo CB, Wong TW, Lai KK. Is public access defibrillation needed in Hong Kong? Hong Kong Med J 2003;9:113-8.

34. Wai AK, Cameron P, Cheung CK, Mak P, Rainer TH. Outof-hospital cardiac arrest in a teaching hospital in Hong Kong: descriptive study using the Utstein style. Hong Kong J Emerg Med 2005;12:148-55. 